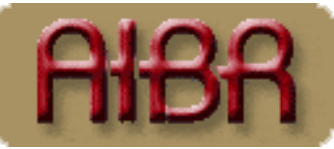

REVISTA DE ANTROPOLOGÍA IBEROAMERICANA

ESTIMADO LECTOR/A:

GRACIAS POR DESCARGAR ESTE ARTÍCULO. EL TEXTO QUE ESTÁ A PUNTO DE CONSULTAR ES DE ACCESO LIBRE Y GRATUITO GRACIAS AL TRABAJO Y LA COLABORACIÓN DESINTERESADA DE UN AMPLIO COLECTIVO DE PROFESIONALES.

USTED PUEDE AYUDARNOS A INCREMENTAR LA CALIDAD Y A MANTENER LA LIBRE DIFUSIÓN DE LOS CONTENIDOS DE ESTA REVISTA A TRAVÉS DE SU INSCRIPCIÓN A LA ASOCIACIÓN AIBR:

http://www.aibr.org/antropologia/aibr/socios.php

La asociación a AIBR tiene un coste mínimo al año, y le proporcionará las siguientes ventajas y privilegios:

1. Recibir en su domicilio la revista impresa, en Europa y América (tres números anuales), así como todas las novedades relativas al funcionamiento de la asociación.

2. Recibir en su domicilio, a precio especial o de forma gratuita, cuantas publicaciones adicionales edite la asociación.

3. Derecho a voto en las asambleas de socios, así como a presentarse como candidato a la elección de su Junta Directiva.

4. Recibir el boletín de socios (tres números anuales), así como la información económica relativa a cuentas anuales de la asociación.

5. Beneficiarse de las reducciones de precio en congresos, cursos, libros y todos aquellos convenios a los que a nivel corporativo AIBR llegue con otras entidades. En este momento, existen los siguientes acuerdos:

o Reducción de un $20 \%$ en el precio de todos los libros publicados por la editorial MELUSINA.

o Reducción de un $20 \%$ en el precio de todos los libros publicados por la editorial SEPHA.

o Reducción de un 30\% en el precio de todos los libros publicados por la editorial GRAN VÍA.

o Derecho a cuota reducida en los congresos trianuales de la FAAEE (España) y a los bianuales de la Sociedad Española de Antropología Aplicada.

o Derecho a cuota reducida en los congresos la IUAES.

6. Promoción gratuita, tanto a través de la revista electrónica como de la revista impresa, de aquellas publicaciones de las que sea autor y que estén registradas con ISBN. La difusión se realiza entre más de 5.000 antropólogos suscritos a la revista.

7. Cuenta de correo electrónico ilimitada de la forma socio@aibr.org, para consultar a través de webmail o cualquier programa externo.

8. Espacio para web personal de la forma http://www.aibr.org/(directorio)/(nombre) y cuenta propia de ftp.

9. Acceso con clave a todos los documentos de la Intranet de socios de AIBR, incluida la consulta a artículos en proceso de evaluación de la revista AIBR.

10. Promoción gratuita a través de la revista (banner rotativo y reseña) de aquellos eventos, congresos, conferencias o cursos en los que usted forme parte del comité organizador.

11. Opción a formar parte como evaluador de los artículos recibidos por la revista.

IMPORTE DE LA CUOTA ANUAL: Hasta diciembre de 2008, la cuota única anual es de 32 (euros). Su validez es de un año a partir del pago de la cuota. Por favor, revise la actualización de cuotas en nuestra web. 


\title{
A.R LA ORgANIZACIÓN DE LOS INMIGRANTES www.aibr.org COMO POTENCIADOR Y/O INHIBIDOR DE SU INSTALACIÓN EN LAS SOCIEDADES DE DESTINO: EL CASO DE LOS COLOMBIANOS EN ESPAÑA ${ }^{1}$
}

\section{Adriana González Gil}

Profesora Asociada, Instituto de Estudios Políticos, Universidad de Antioquia. (Colombia). Dirección: Ciudad Universitaria 14-2009, Medellín (Colombia). Teléfono: (574) 2105690. E-mail: agongil66@hotmail.com

\begin{abstract}
Resumen
La migración colombiana hacia España ha tenido un crecimiento significativo en los años recientes, en razón de la convergencia de factores de distinto orden, entre los que suele destacarse el deterioro de las condiciones económicas y del ordenamiento social y político a partir de la agudización del conflicto armado. Este artículo parte de los rasgos del contexto que, de modo explícito o sutil, subyacen a la explicación de la movilidad de los colombianos y sitúa en el centro del análisis una pregunta por los procesos de instalación del colectivo colombiano en España, en el que cobran especial importancia las prácticas colectivas de los inmigrantes, como una de las dimensiones del proceso de instalación en la sociedad de llegada. Para este propósito, se consideran algunas premisas teóricas que orientan el examen de las iniciativas asociativas ensayadas por los inmigrantes y se plantea una aproximación preliminar a los procesos organizativos de los colombianos en España. Si bien estos procesos no tienen todavía un peso cuantitativo significativo, constituyen un eje importante en la reflexión migratoria, toda vez que pueden hacer parte de una estrategia encaminada a garantizar niveles adecuados de sobrevivencia, de estabilización socioeconómica y/o de vínculo más estrecho con su entorno cultural y social, permitiéndoles al tiempo, mejorar sus condiciones de inserción en la sociedad española. El artículo deja abierto un desafío investigativo, relacionado con la necesidad de examinar las condiciones de los procesos organizativos, su evolución y su impacto, como una arista fundamental en el espectro de las múltiples dimensiones del proceso migratorio.
\end{abstract}

Palabras clave

Migración colombiana, migrantes colombianos en España; contexto de salida, iniciativas asociativas.

\footnotetext{
${ }^{1}$ Esta reflexión es fruto del proyecto de investigación "La diáspora colombiana: derechos humanos y migración forzada Colombia-España 1995-2005. Construcciones sociales, políticas y jurídicas en el fenómeno de la migración forzada", adelantado por el Instituto de Estudios Políticos de la Universidad de Antioquia y la Universidad Pablo de Olavide, Sevilla, con el apoyo financiero de la Agencia Española de Cooperación Internacional AECI.
} 


\begin{abstract}
Colombian migration to Spain has increased significantly in recent years due to the convergence of many different factors; one of the most decisive factors is the deterioration of both economic conditions and social and political contexts due to the worsening of Colombia's armed conflict. This article takes into account the country's circumstances that directly or indirectly underlie the explanation of Colombian's mobility. It also poses a question -as center of the analysis - about the processes of settlement of the Colombian community in Spain, processes in which collective practices play a decisive role.

In order to undertake the analysis, some theoretic concepts are used to examine the associative initiatives attempted by immigrants, and to make a preliminary approach to the organizational processes of Colombians in Spain. Even though these processes are not quantitatively significant yet, they are an important tool for the analysis of migration because they might be part of a strategy used by migrants to achieve adequate levels of survival, to gain social and economic stabilization, and a closer relationship with the new cultural and social milieu, a strategy that would also allow these migrants to improve their conditions of insertion into the Spanish society.

This article seeks to clear the way for an investigative challenge that has to do with the necessity of examining the conditions, evolution and impact of organizational processes, as one of the fundamental aspects of the multidimensional migratory processes.
\end{abstract}

Key words

Colombian migration, Colombian migrants in Spain, context of departure, associative initiatives.

Recibido: 27 de Junio de 2007

Aceptado: 21 de Agosto de 2007

\title{
Introducción
}

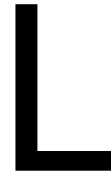

a migración colombiana no es un fenómeno episódico, coyuntural, referido al escalamiento reciente del conflicto armado; ha estado presente en el país desde mediados del siglo XX, momento en el cual estuvo asociada a la evolución de la violencia política, al desarrollo de un modelo económico altamente excluyente y al papel jugado por un Estado que perdía gradualmente su capacidad de garantizar seguridad y vida digna a los ciudadanos. La migración de campesinos a las grandes ciudades como Bogotá, Medellín, Cali, así como aquella migración que traspasó las fronteras nacionales desde la década de 1960, tenían el común denominador de ser provocadas por factores de fuerza como la violencia político partidista que azotó campos y ciudades, generando un clima de inseguridad para la población en su conjunto; como también la fuerza y contundencia de un sistema 
económico que tras su consolidación dejaba a su paso una amplia gama de excluidos. Ese carácter forzado de la migración fue soslayado por el proceso de industrialización en Colombia y por las expectativas de mejoramiento de las condiciones de vida en otros países, en especial y para esa primera ola migratoria, en los Estados Unidos.

No obstante su existencia como un fenómeno de larga data, lo que sí ha resultado novedoso desde 1985 es la magnitud cuantitativa del fenómeno, su articulación con la globalización económica, la militarización internacional y la complejidad que el actual conflicto armado colombiano le imprime, también en términos cualitativos, a los procesos migratorios en el país. Una magnitud descrita como una gran crisis humanitaria que ha obligado a millones de personas a movilizarse de manera forzada dentro de las propias fronteras nacionales, traspasando las fronteras de los países vecinos (Ecuador, Venezuela, Perú, Brasil y Panamá) e instalándose en calidad de inmigrantes legales, ilegales, indocumentados en países norteamericanos y europeos principalmente.

Hay una crisis humanitaria expresada en lo que se ha dado en llamar la diáspora de colombianos $^{2}$ que abandonan su lugar de origen y se dispersan por ciudades colombianas (desplazamiento forzado interno) y por distintas ciudades del mundo (migración económica, refugio, asilo). Esta movilización forzada de población colombiana se expresa en términos cuantitativos de la siguiente manera: en razón del fenómeno del desplazamiento forzado interno se han movilizado 3.83.527 de personas (CODHES Informa No 69: 2006) ; $^{3}$ de igual manera por fuera de las fronteras nacionales viven aproximadamente 3.331.107 de personas (DANE: Censo 2005), muchas de ellas migrantes económicos; así como: 233.600 refugiados, 315.000 refugiados no reconocidos; 16.000 colombianos expulsados, 24.500, repatriados (Comité for Refugees and Immigrants, 2004).

\footnotetext{
${ }^{2}$ Sobre la "emergente diáspora colombiana" especialmente para analizar la migración trasnacional, véase: GUARNIZO, Luis Eduardo. La migración trasnacional colombiana. Implicaciones teóricas y prácticas. En: MISTERIO DE RELACIONES INTERNACIONALES. Colombia nos une. Memorias del Seminario sobre Migración internacional colombiana y la conformación de comunidades trasnacionales. Bogotá: junio de 2003, p. 29.

${ }^{3}$ Según SUR-Sistema Único de Registro (2006), la fuente oficial colombiana, estima que desde antes de 1995 y hasta 31 de mayo de 2006 hay 1.807 .337 personas desplazadas en total. La población total de Colombia según el Censo de 2005 asciende a 41.242 .948 personas (Rojas, 2006). Según el Informe del Defensor del Pueblo al Congreso de la República y los Informes Conjuntos de la Defensoría del Pueblo y de la Procuraduría General de la Nación en el marco del cumplimiento de la sentencia T-025, entre otros, el número de desplazados se aproximaría a unos tres millones. Ver al respecto Comisión de Juristas (2005:7)
} 
Distintos factores explicativos -a manera de hipótesis de trabajo- de la migración forzada en Colombia ofrecen un marco interpretativo común tanto para la migración internacional como para el desplazamiento interno de población, sobre todo en sus marcos contextuales de interpretación (Ministerio de Relaciones Exteriores, Programa Colombia Nos Une, 2003; Consuelo Ahumada Beltrán y Álvaro Moreno Durán, 2005; Roberto Carlos Vidal López, 2005) y construcción de explicaciones, todavía hipotéticas, en relación con los aspectos que vinculan el desplazamiento forzado interno y la migración internacional, en el espectro más amplio de los procesos de movilidad humana que emergen bajo las condiciones de globalización contemporáneas. Cuatro factores sintetizan esta articulación de hipótesis explicativas del proceso migratorio de los años más recientes: la globalización neoliberal, el fortalecimiento del narcotráfico, el conflicto político interno y las precarias condiciones en la garantía de los derechos de ciudadanía en Colombia.

De este modo, si bien la emigración de colombianos ha sido vista con frecuencia como el resultado de una decisión individual de aquellos que con algunas posibilidades -económicas, laborales, sociales- buscan mejorar su situación por fuera del entorno nacional y, a su vez, el desplazamiento interno de población ha sido explicado, con frecuencia, como uno de los rostros de la prolongación y agudización del conflicto armado, como expresión dramática de la guerra o estrategia de la misma, la búsqueda de explicaciones que superen el lugar común de estas afirmaciones, demanda un riguroso tratamiento investigativo que desvele las complejas dimensiones de los procesos de movilidad humana en el contexto colombiano de los años recientes.

En efecto, si bien el desplazamiento interno y la emigración son fenómenos que han estado presentes en épocas anteriores, es sólo en los últimos dos decenios que cobra significativa relevancia; entre otras cosas, porque buena parte de los colombianos que se movilizan lo hacen en razón de condiciones especialmente traumáticas que condicionan o explican su decisión. Boaventura de Sousa Santos (1998) ha subrayado el carácter forzoso de los procesos migratorios contemporáneos ligados estrechamente a la dinámica de la globalización y su impacto sobre el deterioro de las condiciones de vida de gran parte de la población mundial, por lo que no resulta extraño señalar que más allá de la racionalidad que 
tradicionalmente se le atribuye a la decisión migratoria como parte de un cálculo de beneficios personales, es hoy, también, parte de los procesos de movilidad forzada por las circunstancias de orden socioeconómico, político y cultural imperantes.

Abordar los rasgos del fenómeno migratorio en el caso colombiano, en cuanto las posibles conexiones existentes entre el desplazamiento forzado interno, la migración transfronteriza y la migración transnacional, supone hacer visible, en primer término, las dimensiones y rasgos específicos del contexto, y en particular, la forma como éste incide sobre los procesos de instalación o asentamiento en la sociedad o comunidad de destino y sobre la decisión del retorno a la comunidad de origen en los distintos procesos de movilidad. Con esto queremos significar la relevancia que juega en el análisis el contexto de violencia prolongada en el caso colombiano, sin la pretensión de atribuir a éste un carácter de excepcionalidad en la compleja trama de las dinámicas conflictivas del mundo contemporáneo ni como detonante exclusivo o directo de la migración colombiana.

Se trata, en particular, de hacer explícita la importancia que concedemos al contexto como factor explicativo de la evolución y alcance de los procesos organizativos. Para ello establecemos un vínculo importante entre contexto y acción colectiva, el cual no ha sido considerado de modo relevante, sin duda porque los diferentes enfoques teóricos han puesto el acento en preguntas referidas a otras dimensiones del problema. En nuestro caso, y sin pretender señalar un carácter determinante al contexto en función del despliegue de distintas formas de acción colectiva, asumimos de un lado, el desafío de examinar con mayor detalle algunas dimensiones del contexto, más allá del orden institucional/político, especialmente cuando nos hallamos frente a contextos de extrema conflictividad o violencia generalizada; y de otro lado, buscamos explorar las condiciones que explicarían la precaria construcción organizativa de actores sociales emergentes y el limitado impacto de su accionar, en función, particularmente, del carácter violento del conflicto colombiano que no sólo desestimula la acción por la vía de la represión, sino además, por cuanto en el largo plazo la violencia se ha enquistado de tal forma que deviene en rasgo significativo del entorno social y cultural colombiano, condicionando de algún modo las formas que adopta las prácticas sociales de comunidades enteras. 
Dieter Rucht ha llamado la atención sobre la importancia de avanzar en trabajos comparados de los movimientos sociales en contextos diferentes para evaluar el desarrollo e impacto de las acciones colectivas en las condiciones del presente, que desbordan en mucho los enfoques explicativos predominantes en esta materia. En el caso que nos ocupa, una mirada al contexto colombiano supone la articulación de distintas dimensiones y variables del problema, en la pretensión de hacer explícito el modo en que sus particularidades anudan la trama de las movilidades humanas que tienen especial relevancia en los últimos años, no sólo en relación con su magnitud cuantitativa, sino especialmente en función de su diversidad y complejidad, sin que con ello sobredimensionemos la excepcionalidad de su ocurrencia en el contexto mundial.

Con estas precisiones, y en el marco de los propósitos de la investigación " $\mathrm{La}$ diáspora colombiana: derechos humanos, migración forzada", este artículo se ocupa, en primer lugar, de aquellos rasgos del contexto que, de modo explícito o sutil, subyacen a la explicación de la movilidad de los colombianos -como condicionantes, detonantes o inhibidores- pero que en todo caso, concretan rasgos específicos del proceso migratorio en el caso colombiano.

En segundo lugar, se destacan algunos de los rasgos que tipifican la actual coyuntura del flujo migratorio colombiano a España, como uno de los destinos que ha visto incrementar considerablemente la presencia de este colectivo en los últimos cinco años.

En tercer lugar, y como centro de la reflexión, se aborda la que consideramos una de las dimensiones del proceso de instalación en la sociedad de llegada; nos referimos a las iniciativas asociativas ensayadas por los inmigrantes en España, como parte de una estrategia que más allá de garantizar niveles adecuados de sobrevivencia o estabilización socio-económica, deviene en un espacio propicio para reiniciar la vida, dando continuidad así a procesos que los vincula de modo más estrecho con su entorno cultural y social, permitiéndoles al tiempo, mejorar sus condiciones de instalación en la sociedad de llegada.

Finalmente, en el cuarto punto, se hace una aproximación preliminar a los procesos organizativos de los colombianos en España, con la pretensión de dar inicio a una línea de trabajo que estimamos importante pese a que estos procesos 
no tienen todavía un peso cuantitativo significativo. Examinar sus condiciones, su evolución y su impacto constituye un desafío para evitar desestimar su importancia.

\section{La migración internacional de colombianos: condiciones, motivaciones y perfil de los inmigrantes}

El estudio de las migraciones se puede abordar desde un enfoque históricoestructural que permita entender el fenómeno de la migración como un conjunto dinámico que vincula las condiciones de la sociedad de salida con las particularidades de la sociedad de destino, pero que en todo caso, no desestima, sino al contrario, enfatiza una valoración del proceso migratorio como articulación de flujos humanos, más allá de los sujetos asumidos individual y aisladamente. La perspectiva histórica, además, permite identificar las principales transformaciones ocurridas en un marco temporal que explica las condiciones estructurales específicas y su impacto sobre procesos sociales como los de movilidad humana. Así, fenómenos de orden económico, político, cultural y simbólico estarían en la base de un análisis de esta naturaleza, reconociendo, como lo afirma Lorenzo Cachón (2001), que la naturaleza distinta de la migración contemporánea viene determinada, sin duda, por la lógica del mercado y del Estado, pero en estrecha vinculación con el análisis micro que subraya los comportamientos y las decisiones individuales en un marco de relaciones sociales que se constituyen en un nivel de análisis diferenciado y complementario de las estructuras socioeconómicas y políticas (Colectivo IOE, 1999).

Si bien los movimientos poblacionales han sido una constante histórica, las migraciones contemporáneas vienen siendo consideradas en el campo más amplio de los procesos de globalización con las implicaciones que ello supone. Recientemente se asiste a un interés creciente por la dinámica migratoria colombiana, en particular por los procesos de movilidad transfronteriza y transnacional cuyo incremento considerable se visualiza hacia el decenio de 1990, si bien podríamos afirmar, son la otra cara de los procesos de movilidad humana con rasgos marcadamente dramáticos como sucede con los desplazamientos forzados internos que ascienden a más de tres millones de colombianos en los últimos veinte 
años ${ }^{4}$. Este crecimiento desmedido y el drama humanitario que representa, explica, sin duda, la mayor relevancia que han tenido los estudios sobre el fenómeno del desplazamiento interno. De otro lado, la migración de colombianos hacia el exterior, aparece en el debate público en estos años, no en razón de consideraciones humanitarias, sino especialmente, por las implicaciones de las remesas en la economía del país. Ello ha abierto preguntas importantes, aún sin resolver completamente, relacionadas con la migración como factor de desarrollo, o mejor, como mitigador de la pobreza en Colombia.

De este modo, la dinámica del conflicto en la coyuntura más reciente, el deterioro de las condiciones socioeconómicas de buena parte de la población colombiana y los vínculos con procesos continentales y globales, ponen en evidencia la migración forzada de población, no sólo en los contornos del territorio nacional, sino también, y con importancia creciente, hacia países fronterizos (Ahumada y Moreno, 2005) e incluso hacia otros destinos (Garay, 2006). Por ello, se asume aquí una perspectiva de análisis que entiende los procesos migratorios transnacionales e internos- insertos en el más amplio espacio de lo social y de sus reconfiguraciones contemporáneas (Ramírez y Ramírez, 2005).

Así, la migración internacional colombiana es parte del llamado nuevo orden global que favorece la libre circulación del capital y las mercancías, mientras que obstaculiza la movilidad de las personas. Asimismo, las estrategias globales de seguridad y lucha contra el terrorismo que sirven de marco a las medidas adoptadas en el escenario nacional -la actual política de seguridad democrática y el desarrollo del Plan Patriota en el sur del país-; así como el proceso de desmovilización de los grupos paramilitares, la disputa por el control de territorios estratégicos entre los distintos grupos armados, el traslado de cultivos hacia zonas controladas por actores armados al margen de la ley, la situación de inseguridad alimentaría derivada de las fumigaciones, de los bloqueos o confinamientos, son entre otros, factores que profundizan la migración forzada interna, transfronteriza y transnacional (CODHES INFORMA, 2004).

\footnotetext{
${ }^{4}$ Hasta el momento el gobierno colombiano admite que entre el primero de enero de 1995 y el 30 de junio de 2005, un total de $\mathbf{1 . 8 7 7 . 3 2 8}$ personas desplazadas están inscritas en el Sistema Único de Registro (SUR). El Sistema de Información sobre Desplazamiento Forzado y Derechos Humanos SISDHES, que opera CODHES desde 1995 y que recoge la cifra de la Conferencia Episcopal de Colombia del período 1985-1994, indica que alrededor de $\mathbf{3 . 8 3 2 . 5 2 7}$ personas han sido desplazadas en los últimos 20 años (primero de enero de 1985 y el 30 de junio de 2006).
} 
El flujo migratorio colombiano ${ }^{5}$, a partir de 1990, ha estado asociado en el incremento de su volumen a múltiples factores internos y externos, tales como: el deterioro de la economía nacional, especialmente desde finales de los ochentas e inicios de los noventas como consecuencia de la adopción de reformas estructurales de corte neoliberal a nivel nacional, que desataron, entre otras cosas, la quiebra masiva de miles de empresas privadas incapaces de competir ante la apertura económica. A esto se unió el colapso en los precios internacionales del café con el consecuente debilitamiento de la economía cafetera, la quiebra a miles de productores, el aumento del desempleo y la reducción de una de las principales entradas de divisas del país. Adicionalmente, las reformas incluyeron recortes significativos en la nómina de empleados oficiales y despidos derivados de la privatización de empresas públicas; esta situación unida al aumento del número de personas con títulos universitarios desempleados o subempleados incrementó las tasas históricas de desempleo abierto y de informalidad económica.

Además del deterioro económico, el país enfrentó una profundización de la crisis en los órdenes político, social y militar. La generalización de la violencia violencia política, delincuencia común, de la droga- a lo largo y ancho del territorio nacional, contribuyó a generar un ambiente de inseguridad e incertidumbre en el que la emigración surgía como una salida viable y recomendable para sectores cada vez más amplios de la sociedad. Como señala Guarnizo (2003), dos factores adicionales, uno de tipo macro y el otro de tipo micro estructural, contribuyeron de manera significativa a generar las condiciones para la masificación de la emigración colombiana. A nivel macro, la consolidación y expansión del mercado internacional de las drogas coadyuvó en este proceso. En efecto, el aumento de la demanda y oferta de drogas ilícitas generó a su vez una demanda creciente de mano de obra para trabajar en el negocio, permitiendo la salida de gente que de otra forma no hubiese podido salir y la permanencia en el exterior de gente que hubiese tenido que regresar por sus condiciones de precariedad económica en el exterior. Aunque la proporción de migrantes conectados con el tráfico de drogas es relativamente pequeño, el estigma del tráfico ha marcado a los emigrantes, particularmente desde los ochentas, no solamente en los países de destino sino también en Colombia.

\footnotetext{
${ }^{5}$ Se retoma aquí aspectos del trabajo de Gloria Naranjo y Deicy Hurtado. "Contextos explicativos de la migración forzada en Colombia: desplazamiento interno, migración transfronteriza y migración transnacional". En: Universidad Pablo de Olavide-Universidad de Antioquia, Op. cit.
} 
Asociado directa e indirectamente con la emigración ligada al tráfico ilícito de drogas, se expande también otro tipo de emigración, que aunque mucho menos numerosa, ha resultado muy nefasta para la imagen de los colombianos en el exterior: la migración ligada a la delincuencia común. Algunas redes de delincuentes de las grandes ciudades colombianas, tomaron el rumbo hacia metrópolis norteamericanas y europeas, en no pocos casos contratados por carteles del narcotráfico, en donde hoy en día han establecido operaciones delictivas de alguna relevancia.

A nivel micro estructural, la consolidación y maduración de las redes sociales transnacionales que sirven para allanar el camino de los flujos recientes de colombianos orientando su destino final. Familiares, amigos, vecinos, y paisanos radicados en el exterior abren puertas y facilitan la salida para aquellos cuyas vidas y expectativas en el país resultan insostenibles. La vieja generación de migrantes provee apoyo logístico e informativo para los recién llegados que va desde dar información sobre el sistema migratorio y la sociedad receptora en general, hasta la provisión de apoyo legal, vivienda, empleo y préstamos para financiar el trayecto migratorio.

Pero, ¿qué sectores poblacionales están emigrando? El crecimiento de la emigración colombiana revela que gente de todo tipo ha salido del país: obreros y profesionales en busca de mejores ingresos; empresarios en busca de seguridad y estabilidad; personas acosadas por su posición de clase o por sus posiciones políticas; refugiados de izquierda y de derecha; perseguidos y perseguidores (Guarnizo, 2003: 33). La última ola emigratoria colombiana, evidentemente la más grande en la historia del país, está conformada en alta proporción por personas con un nivel de escolaridad más alto de la media nacional -profesionales con títulos universitarios, pequeños y medianos empresarios, jóvenes de clase media a continuar sus estudios en el exterior; pero también, en grado importante personas de sectores marginados de la sociedad, incluyendo aquellos con prontuarios delictivos.

En relación con la procedencia de los migrantes (Guarnizo, 2003: 35), aunque todas las regiones del país están representadas en esta diáspora en formación, tanto en los Estados Unidos como en Europa, la emigración colombiana es ante todo una migración urbana y proveniente de las áreas más desarrolladas del país, esto es, las más conectadas al sistema económico nacional y mundial como Bogotá, Cali, Medellín, Pereira (incluyendo Dosquebradas) y Bucaramanga. 


\section{Los inmigrantes colombianos en España ${ }^{6}$}

Si bien es posible identificar móviles personales y condicionantes sociales que explican el crecimiento del flujo migratorio colombiano hacia España, no está por demás señalar que junto a los motivos, principalmente económicos, que determinan la emigración colombiana, corre también paralela la demanda de mano de obra que se observa en España a partir de 1995, por el gran crecimiento de su economía y la mayor incorporación de la mujer española al mercado laboral. Este proceso de crecimiento económico señala una nueva organización de la producción y la reestructuración del mercado de trabajo, que deriva en necesidad de mano de obra flexible y que acepte bajas remuneraciones para cubrir las demandas de la tercerización de los centros urbanos y las transformaciones de los sectores agrícolas (Pedone, 2006: 55-57). En esta aproximación inicial se ha observado, precisamente, que es en estos sectores laborales en los que van a ubicarse, mayoritariamente, los colombianos que llegan a España.

Bajo estas condiciones, puede afirmarse que la emigración masiva a territorio español por parte de personas colombianas es un proceso más bien reciente, tal como lo revelan los datos de estadísticas y estudios de investigación realizados tanto en Colombia como en España. Específicamente, el investigador Luís Jorge Garay (2006: 6) señala que "la migración del colectivo colombiano a España es un fenómeno reciente, creciente y sujeto a una constante transformación [que] precisa una atención y análisis continuados". Por su parte, la investigación de Adriano Díez (2006) identifica dos períodos en la inmigración de colombianos en España: el primero, entre 1995 y 1999 cuando el tamaño de este colectivo crece gradualmente; el segundo, desde 2000, cuando el tamaño de la población colombiana en España crece rápidamente duplicando su tamaño de año en año.

Las cifras oficiales reflejan también este crecimiento. Los resultados del Censo General de Colombia de 2005, muestran que España ocupa el segundo lugar (23.3\%) entre los países de destino de las personas colombianas que residen

\footnotetext{
${ }^{6}$ En este apartado se retoman aspectos del trabajo de Pilar Cruz. "Aproximación a los flujos y tipologías de la migración colombiana en España, 1996-2006". En: Universidad Pablo de Olavide, Universidad de Antioquia, 2007, Op. cit.
} 
en el exterior, después de Estados Unidos (35,4\%) ${ }^{7}$. De acuerdo con los datos del INE (2007), el colectivo colombiano ocupa el cuarto lugar más numeroso entre los extranjeros no comunitarios residentes en España, por detrás de los nacionales de Marruecos, Ecuador y Rumania, con un total de 265.141 personas (6,40\%). No obstante, estas cifras oficiales, no reflejan completamente la magnitud de la migración colombiana, porque entre los inmigrantes colombianos se aprecia un considerable índice de migración irregular ${ }^{8}$.

De otra parte, y en una primera exploración que nos permita caracterizar la inmigración de colombianos en España, así como precisar sus condiciones de instalación en este país, podría afirmarse que el colectivo inmigrante colombiano está conformado por cuatro grupos, cuyas situaciones estarían bastante diferenciadas 9 : los inmigrantes por motivos laborales o que buscan mejores condiciones de vida (la mayor parte de los inmigrantes colombianos habrían llegado por este motivo); los inmigrantes por razones familiares (casos de reagrupaciones o reunificaciones); los inmigrantes que por razones políticas y por el peligro que corre su seguridad en Colombia llegan en busca de asilo y refugio y los inmigrantes por motivos de estudio.

Esta clasificación se ve reflejada en los resultados que arrojan dos investigaciones realizadas recientemente entre inmigrantes colombianos en la Comunidad de Madrid. Así, el 75\% de los tres mil encuestados en la investigación del Instituto Ortega y Gasset señaló que su motivación para dirigirse a España fue la situación económica y la búsqueda de trabajo, mientras que sólo el 4,2\% se refirió a la violencia y la inseguridad como la principal razón que los impulsó para abandonar Colombia. Así mismo, en la investigación de Garay dos de cada tres encuestados indicó que la búsqueda de trabajo y la falta de oportunidades los motivó a emigrar de Colombia (específicamente $49 \%$ lo hizo para buscar trabajo, $11 \%$ por falta de

\footnotetext{
${ }^{7}$ Los otros países de destino son: Venezuela (18.5 \%), Ecuador (2.4\%), Canadá (2,2\%) y con porcentajes mucho menores Panamá, Costa Rica, México y Australia (DANE, 2005).

${ }^{8}$ Cfr. Para 2002 el estudio de las Universidades Comillas y Autónoma de Madrid estima en 350.000 los inmigrantes colombianos en España de los que 120.000 estarían en situación regular o a la espera de estarlo y los 230.000 restantes, en situación irregular. Otras fuentes señalan que en territorio español viven unos 738.000 colombianos (según datos de Colombia) o cerca de 500.000 según fuentes españolas que confirman la presencia de 100.000 regularizados, afirmando además, que por cada colombiano regularizado hay dos irregulares viviendo en España. Noticias Hispavista (2006) y Puyol (2006).

Esta tipología se basa en las distinciones que ofrece Cristina Blanco (2004: 40) para caracterizar las nuevas tendencias de la migración internacional.
} 
oportunidades, 6\% para hacer negocios); los otros motivos que adujeron fueron familiares (25\% entre reunirse y acompañar familiares), así como estudiar (5\%).

En cuanto al lugar de residencia en España, los motivos laborales determinan, principalmente, la concentración de la población extranjera en las grandes poblaciones, entendiéndose por tal a las capitales de provincia y las grandes ciudades españolas como Madrid o Barcelona, pero también en localidades pequeñas donde las actividades laborales predominantes demandan mano de obra como las poblaciones turísticas y poblaciones que necesitan mano de obra agrícola (Murcia y Almería). Asimismo, la necesidad de buscar una mejor oportunidad laboral también determina la gran movilidad que se observa en la población extranjera que reside en España (Pumares, García y Asensio, 2006). El caso de la población colombiana no resulta distinto a este patrón de poblamiento, observándose, por un lado, una tendencia a concentrarse sobre todo en las grandes urbes (Madrid y Barcelona), así como por otro lado a presentar una gran movilidad. Entre 1998 y 2006 las cinco Comunidades Autónomas que registran el volumen más alto de colombianos entre su población residente son: Comunidad de Madrid, Cataluña, Andalucía, Comunidad Valenciana y Canarias, seguidas luego, alternativamente, de Castilla y León, País Vasco y Castilla-La Mancha.

Ahora bien, en la investigación que adelantamos, más allá de la intención de sistematizar el proceso migratorio transnacional de colombianos hacia España durante el período 1995-2005, en el que se enfaticen aspectos como el respeto y cumplimiento de los derechos humanos y, el modo en que las políticas migratorias se ven interpeladas por el colectivo de inmigrantes, en cuanto la experiencia ha demostrado que la normatividad, tanto nacional como internacional vigente, se ve claramente desbordada por la realidad de los inmigrantes; hemos dado especial importancia al análisis de las condiciones -contexto local e internacional- de salida y de destino de los inmigrantes, a la configuración de redes y a la adopción de estrategias y acciones de los inmigrantes en la perspectiva de organizarse para demandar una respuesta positiva a su situación. Así, el énfasis del trabajo está en el que denominamos aquí proceso de instalación/inserción ${ }^{10}$ del colectivo colombiano

\footnotetext{
${ }^{10}$ Hacemos referencia específicamente a las condiciones y desafíos que enfrentan los inmigrantes colombianos residentes en España y a las estrategias que adoptan para instalarse en este país, en términos de vivencia personal, familiar y social. No abordamos la discusión de orden teórico que distingue en el fenómeno migratorio las implicaciones socio-políticas y culturales de los llamados procesos de asimilación, aculturación, integración.
} 
de inmigrantes residentes en España; proceso que supone abordar, en nuestro caso, tres dimensiones específicas: las formas organizativas adoptadas, las prácticas socio-políticas (redes, acción colectiva) y las dinámicas culturales que permiten a los inmigrantes construir vínculos sociales centrados en el reconocimiento, la inclusión, la equidad y la justicia.

Esta dimensión organizativa supone examinar el proceso de configuración e identificación como actores colectivos de la población inmigrante, su proceso de articulación y organización en las sociedades de destino y las distintas estrategias y acciones que despliegan para demandar respuestas a su problemática y reiniciar su vida en el nuevo contexto en el que están inmersos. Esto reviste un interés particular, de orden teórico y en la perspectiva de interpretación del tema migratorio, especialmente por tratarse de procesos organizativos que discurren en un contexto de movilidad permanente.

Particularmente, interesa identificar algunos de los rasgos que definen el modo en que los inmigrantes viven y trabajan en una sociedad diferente a la de su origen, de qué maneras enfrentan los desafíos de esa nueva realidad y cómo construyen espacios públicos nuevos para la solución colectiva de problemas también públicos, por los que son especialmente afectados. Lo anterior, por cuanto uno de los objetivos centrales de esta investigación es valorar las condiciones específicas de su proceso de inserción, sin duda desigual, en un país como España, al tiempo que se plantean iniciativas en procura de mejores condiciones de vida y de denuncias de los abusos de los que son víctimas; pero también, en cuanto a su potencial participativo y organizativo que podría conducir a favorecer una inserción menos traumática en la sociedad receptora.

A partir de exploraciones preliminares y de algunos estudios realizados puede constatarse la existencia de diversas iniciativas colectivas de los inmigrantes, que, sin embargo, presentan diferenciales y desiguales recursos organizativos, formas de acción social y perspectivas políticas. De manera simultánea, se puede observar una tendencia a vivir en la sociedad de destino adoptando un bajo perfil organizativo, con la intención de hacer menos visible su procedencia y las razones de su salida del país, además de aprovechar los posibles beneficios del anonimato en el país receptor. Esta gama de expresiones de inserción de los inmigrantes colombianos en España, constituye una razón para explorar e interpretar las diferentes dinámicas del 
proceso organizativo que vincula a la población inmigrante en su lugar de destino y su posible vínculo con aprendizajes previos en su contexto de salida.

Entre los múltiples problemas que supone el proceso de inserción en la sociedad de destino, nos interesa, en particular, explorar las condiciones del proceso organizativo que jalonan los inmigrantes, bien como medidas episódicas tendentes a buscar mejores alternativas para hacer frente a las dificultades que supone su llegada e instalación, o bien como fórmulas de resistencia y autoprotección debido a su movilidad hacia otros territorios. El tratamiento de estos aspectos constituye el punto central del artículo, sintetizado en los apartados siguientes.

\section{Los procesos organizativos de inmigrantes en las sociedades de destino: premisas para su interpretación}

Si bien entendemos que la puesta en marcha de iniciativas organizativas no constituye en sí mismo un rasgo definitivo de constitución de un actor colectivo plenamente identificado por parte de los inmigrantes, tampoco desestimamos el papel que puede jugar esta tendencia en relación con el proceso de instalación en la sociedad española.

Ahora bien, no partimos de un supuesto nivel de organización (alto o bajo), ni de un proceso consolidado o emergente, simplemente nos preguntamos por las prácticas asociativas que vinculan a la población inmigrante alrededor de proyectos, programas o acciones puntuales, en la perspectiva de cómo los inmigrantes, al iniciar o dinamizar procesos organizativos, pueden también estar intentando construir, mantener o reconstruir formas comunitarias que les permita hacer efectivos sus derechos de identidad y sentido de pertenencia, articulando dinámicas de solidaridad, relaciones con las comunidades receptoras y buscando potenciar el manejo de recursos escasos, en la perspectiva de mejorar su bienestar y lograr el reconocimiento de la sociedad y el Estado receptor.

En tal dirección, no se asume, por anticipado, la existencia de la población inmigrante organizada como grupo social plenamente constituido, ni se supone su cohesión y articulación a procesos sociales más amplios; se trata de explorar las condiciones en que emergen como colectivo, las circunstancias que favorecen su identificación y asunción de su autonomía, su potencial para organizarse y los rasgos que definen sus actuaciones, en el marco de un repertorio de acciones 
históricas o inéditas. No obstante, ese precario proceso de identificación colectiva no desconoce la existencia de grupos de inmigrantes que provienen de la misma región, familia o comunidad, y en consecuencia, comparten rasgos específicos que cobran sentido en su proceso de configuración como actores colectivos.

En esta perspectiva, es posible formular algunas premisas teóricas para la interpretación de los procesos organizativos de los inmigrantes en las sociedades de llegada, veamos:

A) El enfoque de la movilización de recursos. Desde los aportes de este enfoque, aspectos como la disponibilidad de recursos, las estrategias de movilización, las formas de organización interna, la construcción de redes de solidaridad y de comunicación, estarían en la base de un examen del proceso que conduce a los inmigrantes a organizarse. Más allá de la existencia de los agravios como detonante de la movilización, se trataría de indagar por las condiciones que hacen posible la vinculación de los actores a la acción, y en cuyo marco el tema de la organización cobra gran importancia. La organización concebida no sólo de modo logístico, burocrático, en cuya perspectiva tiene gran importancia al papel de los agentes como promotores de la acción para organizarse y la estructura como forma de agrupación de los recursos, de definición de los objetivos y de las estrategias; sino además, la organización como espacio de construcción de vínculos internos que cohesionan el grupo.

De igual modo, rastrear asuntos como la conciencia que tienen los grupos acerca de los intereses que los moviliza, las formas como concretan lazos de solidaridad y pertenencia y las estrategias de movilización, en la perspectiva de abordar las condiciones sociales de la movilización, permite entender en los términos de Tilly (1978), que un grupo estará mejor organizado para la defensa de lo que percibe como sus intereses, en la medida que sus redes de sociabilidad voluntarias permitan construir identidades en función de condiciones objetivas.

Ahora bien, en el proceso de configuración de una identidad de ese potencial actor colectivo, resulta relevante considerar los llamados marcos de la acción colectiva, definidos como la existencia de constantes culturales y referentes construidos por los actores, como significados compartidos que estimulan las razones para implicarse en la acción; confianza, lazos de cooperación, discursos culturales, son elementos que conectan a los actores y los impulsan a la acción. 
En este aspecto, y siguiendo a Melucci es importante acercarse a los procesos de reconocimiento y configuración de la identidad de los actores, como factor decisivo en el proceso de construcción social de la acción colectiva. Este proceso supone considerar al colectivo de inmigrantes como generador de códigos culturales alternativos a los dominantes, que permita identificar los rasgos que definen la acción como un proceso en construcción y no como un punto de partida ya determinado. Acercarse al proceso de construcción de un actor colectivo entre la población inmigrante, identificando en él la interacción, los intercambios, las negociaciones y el momento de toma de decisiones, que conduce a los actores individualmente concebidos a adoptar mecanismos que los vincule y los comprometa colectivamente; se trata de explicar el modo como los inmigrantes llegan a una definición interactiva y compartida del significado y los objetivos de su acción, en el camino de construir un nosotros, la más de las veces dentro de procesos de negociación de intereses opuestos.

En esta perspectiva analítica, el tránsito de lo individual a lo colectivo, el asunto de cómo se implican los actores alrededor de intereses comunes, o en otros términos, de cómo se configura un actor colectivo, constituye un desafío de primer orden si se quiere indagar ese proceso en un conglomerado como el de la población inmigrante, mucho más si consideramos, como lo hacemos acá, que su existencia no es un hecho en sí mismo, sino un proceso que debe ser explorado en todas y cada una de sus dimensiones y momentos.

En síntesis, se trata de indagar aquí por las lógicas organizativas y las dinámicas institucionales que conducen a los inmigrantes a implicarse en específicos espacios públicos y dispositivos de participación y asociación, que más allá de contribuir a la solución inmediata del problema potencie un proceso de articulación a otros asuntos de orden colectivo e institucional. La cuestión central que subyace a esta exploración, es entonces, si la población inmigrante vive un proceso de constitución como actor colectivo (social y político).

B) La perspectiva del asociacionismo. Desde otra perspectiva, y una de las líneas teóricas contemporáneas en torno al fenómeno asociativo, es aquella que ve a las asociaciones como el actor protagonista de la sociedad civil y como elemento de renovación de los sistemas democráticos (Subirats, 1999; Barber, 2000; Etzioni , 2005). Interesa en esta exploración el potencial organizativo de la población 
inmigrante y el proceso de identificación y construcción de sociabilidades, en la perspectiva de su papel en la sociedad de destino y en relación con sus vínculos con la sociedad de partida. Una tendencia al asociacionismo que por supuesto estará determinada por las condiciones de la dinámica migratoria presente.

Pero, ¿cómo se define en particular, el proceso de adscripción de la población inmigrante? ¿qué tipo de intereses comunes vinculan a los inmigrantes para garantizar su voluntad de asociarse? ¿en qué medida el asociacionismo de la población inmigrante favorece la conquista de reivindicaciones específicas de este colectivo, o bien, en qué medida se articulan a movilizaciones más universales?

La tendencia al asociacionismo como una forma de representación de los intereses de los diferentes grupos existentes en una sociedad y como un mecanismo de información y de participación en la vida política, evitando que los hombres actúen aisladamente (Tocqueville, 2002) , permite abordar el estudio de las dificultades que los inmigrantes tienen que superar en el proceso de instalación e inserción en la sociedad de destino: el asociacionismo permite superar el aislamiento social, fomentar la sociabilidad, intercambiar experiencias y encontrar referentes que les permitan una efectiva integración en la sociedad.

En las primeras fases del proceso migratorio, esta necesidad se acentúa por la sensación de aislamiento y soledad que provoca enfrentarse a un entorno desconocido, que en no pocas ocasiones se percibe como hostil. Las asociaciones de inmigrantes, facilitan un marco de pertenencia que proporciona seguridad: en ellas, el inmigrante, puede ser «persona entre personas», no un «extraño entre extraños»; en ellas puede ser «valorado por sí mismo», no en función de los estereotipos que la mayoría asigna al colectivo de pertenencia del inmigrante. Por todo ello, el asociacionismo entre inmigrantes responde, en gran medida, a un «imperativo afectivo» de sus miembros. La asociación representa el espacio en el que se destruye el aislamiento social que supone vivir en las coordenadas clásicas de la inmigración (Sánchez Herrera, 2006).

Pero también es cierto que los papeles de las asociaciones son ambivalentes, ya que al mismo tiempo pueden dificultar la integración en la sociedad receptora en la medida que comportan replegamiento y tienden a reproducir los esquemas propios de la sociedad de origen. Esto no impide reconocer que las asociaciones, a menudo, actúan como catalizadores del proceso de integración social de los 
inmigrantes. Las asociaciones voluntarias de inmigrantes son una manifestación necesaria de su asentamiento que, lejos de dificultar la integración de los grupos minoritarios, facilitan la negociación de su participación y su integración efectiva.

Si bien las asociaciones, entendidas como una forma de vertebrar la minoría y defender sus intereses, es decir, como una base para la acción colectiva, pueden incidir favorablemente en el proceso de integración social, es necesario que las asociaciones eviten institucionalizar estructuras paralelas que podrían derivar en una guetización.

Esta doble faz del asociacionismo -facilitador o inhibidor de la integración social-, intermediarias entre los aparatos estatales y los proyectos y necesidades individuales, constituye un elemento importante en el proceso diverso de configuración de formas asociativas de la población inmigrante; proceso contradictorio que subyace a la compleja construcción identitaria de este colectivo.

Entendemos entonces, que una de las expresiones de la presencia e instalación de los inmigrantes es la creación, voluntaria o inducida, de asociaciones que irán definiendo papeles diferentes según el momento, el contexto y el grado de consolidación alcanzado. Pero además, esta tendencia asociativa puede favorecer el proceso de integración o dificultarlo.

Estas observaciones sobre las asociaciones y la tendencia de los inmigrantes a organizarse colectivamente, nos conecta con un asunto especialmente relevante: el proceso de configuración como actor social y político del inmigrante; ello significa, desde nuestra perspectiva, analizar las particulares formas de identificación que justamente preceden a cualquier posibilidad de organización. Esto es, la condición de inmigrante no supone de suyo la existencia de rasgos de identificación que cohesionen colectivamente al grupo, es en el proceso de evolución del proyecto migratorio que se gesta al tiempo la construcción de un nosotros que permitirá tal cohesión, más allá de los rasgos de identificación previos, como la pertenencia a una determinada comunidad étnica y cultural, y en relación estrecha con su situación de inmigrante como elemento común de identificación.

Así como en el proceso de configuración de los movimientos sociales, su politización deviene de la experiencia de una situación injusta compartida por un colectivo de individuos que en los términos de Tilly (1990) definen intereses comunes que preceden a la formación de su identidad colectiva, la idea según la 
cual los inmigrantes establecen lazos de cooperación y asociación política en la sociedad donde residen se basa en el supuesto de que existen intereses específicos de los inmigrantes que buscan reivindicar a través de mecanismos como el de la organización. Esto implicaría que la definición de un interés compartido precede a la formación de una identidad colectiva del inmigrante como actor político. Sin embargo, como actor social ya activo en la vida laboral y cotidiana del país de destino, el inmigrante construye lazos con compatriotas y con otros inmigrantes, con lo cual podría visualizarse un proceso de construcción como actor social y político, de modo simultáneo y estrechamente interrelacionado.

Precisamente, en el proceso de identificación de la población inmigrante, desde su condición particular -que se expresa en fundamentalismos, racismo y xenofobia, de negación de reconocimiento e infravaloración por parte de comunidades en la sociedad de destino-, va emergiendo una especie de "identidad del inmigrante", a partir, especialmente, de una situación compartida de exclusión social y precariedad extrema. Ello desata, por ejemplo, reacciones de la sociedad receptora que se mueven entre el rechazo al extraño y la solidaridad con los inmigrantes. En este último caso, las agendas de los diferentes movimientos pro inmigrantes, incluyen entre sus reivindicaciones el derecho a la pertenencia, a la igualdad y a la no discriminación. En este sentido, puede afirmarse que los inmigrantes aparecen hoy incluidos entre las multitudes de luchas por justicia social y reconocimiento. Sin embargo, y como lo advierte Mezzadra (2005), hay que evitar convertir la figura del inmigrante de modo romántico en un actor "revolucionario", generador del cambio social, sin que ello signifique subestimar su potencial político, en tanto desafían el modelo de Estado Nacional culturalmente homogéneo, en cuanto buscan ampliar el espacio ciudadano -acceso a derechos- y demandas de reconocimiento cultural en el sentido de estar poniendo en el debate político/público la necesidad de construir identidades de grupo y de pertenencias más híbridas.

En tal dirección, el proceso de configuración del inmigrante como actor colectivo plenamente identificado, supone, de un lado, su integración como actor social en la sociedad de destino, construyendo y fortaleciendo lazos de interacción con otros que comparten su situación y generando, entre otras, acciones de cooperación; y de otro, su identificación en virtud de la experiencia migratoria compartida, lo que induce un momento de asunción de las condiciones específicas 
en las que se ve inmerso -exclusión, marginalidad, subordinación- que potencia, probablemente, su constitución como actor político.

C) El enfoque de las redes sociales ofrece sin duda, una opción interpretativa importante a la dinámica migratoria contemporánea. Se trata, específicamente, del contexto político y del papel que cumplen las políticas migratorias en los países receptores para controlar el ingreso de inmigrantes, situación que sin duda, determina el proceso de configuración de las redes (Pedone, 2003) ${ }^{11}$.

El enfoque de cadenas y redes migratorias, nos permite hacer viable una interpretación del problema migratorio que supera los análisis que han subrayado el carácter económico de la migración y soslayado asuntos asociados al comportamiento y la experiencia de los actores, lo que sin duda está en la base de la complejidad de la trama migratoria de los años más recientes. Desde nuestra perspectiva, como lo enfatiza Claudia Pedone (2003:106), interesa precisamente, considerar a los inmigrantes como sujetos capaces de crear y llevar adelante estrategias migratorias para moverse entre contextos micro y macroestructurales en la actual fase del capitalismo.

En este sentido, las redes migratorias vinculan de manera dinámica las poblaciones de la sociedad de origen y la de llegada y trascienden a los actores individuales, lo que supone abordar las especificidades de su conformación como red, los contextos sociopolíticos, económicos y culturales que le son propios y los diversos modos de actuación en la sociedad de destino. El análisis de redes migratorias evidencia que estas vienen marcadas por flujos basados en redes familiares, de amistad o personales que facilitan la entrada en el lugar de destino; permite desmontar el discurso homogeneizador e individualista según el cual, los sujetos se mueven en función de opciones individuales basadas en el cálculo racional del beneficio personal, y por el contrario, permite explicar las motivaciones políticas, económicas y sociales que dan lugar a los movimientos migratorios (Grau e Ibarra, 2003).

La configuración de redes y cadenas migratorias, más allá de facilitar el proyecto migratorio, deviene también en aprendizaje previo a la tendencia

${ }^{11}$ Como lo señala Claudia Pedone, el análisis de redes sociales tuvo, entre sus primeras aplicaciones prácticas, como campo de estudio, el análisis de redes migratorias. Wellman, B. "El análisis estructural: del método y la metáfora a la teoría y la sustancia", en Política y Sociedad, "Análisis de redes sociales" No. 33 enero-mayo, 2000. 
organizativa que emerge de los colectivos instalados en la sociedad de destino. No resulta circunstancial entonces, que el fortalecimiento de las redes facilite el empeño de la conformación de organizaciones de inmigrantes para garantizar, de un lado, el éxito de futuros trayectos $y$, de otro lado, el complejo proceso de estabilización socioeconómica en el nuevo contexto.

\section{A modo de conclusión: aproximación a los procesos organizativos de los colombianos en España}

El proceso de instalación en la sociedad de destino es sin duda lento y traumático; compromete además, asuntos de orden económico, laboral, familiar, político, social y cultural. En este marco, los procesos asociativos de la población inmigrante residente en España han venido avanzando en los años más recientes, motivados, sin duda, por circunstancias que favorecieron esta tendencia a la organización como opción para acceder a trámites legales que hicieran posible su vinculación activa a la economía española. Este proceso no es homogéneo ni adopta similares condiciones entre los colectivos residentes; y aunque nos interesa abordar el proceso seguido por los inmigrantes colombianos, no desestimamos su cercanía con procesos adelantados por otros colectivos, especialmente de latinoamericanos.

En los balances realizados por los propios inmigrantes, en encuentros de diversos colectivos ${ }^{12}$, es posible identificar algunos rasgos que tipifican el tipo de organización construida, los obstáculos que este proceso enfrenta y las fortalezas con las que cuenta. Subrayan que si bien existe una voluntad para organizarse, falta todavía mucho compromiso con las organizaciones para garantizar su continuidad en el tiempo. Rasgos como experiencia acumulada en el trabajo organizativo, diversidad y heterogeneidad de las asociaciones, integración a plataformas de trabajo más amplias -incluso a nivel europeo- y su potencial para convertirse en auténticos movimientos sociales, constituyen algunos de los rasgos positivos de su proceso organizativo.

\footnotetext{
12 Encuentro sobre Asociacionismo de la población inmigrante en Andalucía. Sevilla, 11 y 12 de noviembre de 2006; Jornadas de formación y reflexión para asociaciones de inmigrantes y refugiados: "El asociacionismo como herramienta para la participación ciudadana". Encuentro Estatal Madrid, 18 y 19 de noviembre de 2006.
} 
Se cuestiona el carácter paternalista de algunas iniciativas en pro de la organización de la población inmigrante surgidas desde ONG's que, pretendiendo extender lazos de solidaridad, resultan trasladando experiencias de modo inconsulto y sin considerar las particularidades de los colectivos y su procedencia socioeconómica y cultural. Por ello, aunque reconocen ese esfuerzo, en el que incluyen algunas acciones desatadas desde la Comisión Española de Ayuda al Refugiado -CEAR-, proponen examinar de modo más preciso cada experiencia en función de las condiciones concretas de los colectivos y las distintas Comunidades Autónomas, entre otras cosas, porque su instalación está en buena medida definida por el contexto favorable u hostil que encuentran en su lugar de destino.

Se destaca igualmente, el papel que empieza a jugar la tendencia a conformar redes asociativas mayores, tipo federación, que articule el trabajo de los distintos colectivos y propenda por su vinculación a reivindicaciones de mayor alcance en términos territoriales y en función de objetivos mucho más universales que la solución inmediata a su situación. En este sentido, se destaca el trabajo que viene desarrollando FERINE, con el apoyo de CEAR, como un paso importante hacia la constitución de una opción organizativa de carácter estatal ${ }^{13}$.

Para el caso de los colombianos residentes en España, si bien, no es posible en este artículo dar cuenta de todos estos aspectos, subrayamos eso sí, el papel que concedemos a las iniciativas asociativas, como parte del despliegue de estrategias que contribuyen a su instalación y adaptación en la sociedad de llegada. En este sentido, esta primera aproximación al fenómeno nos permite señalar algunos de los rasgos que tipifican este proceso, los cuales no son más que hipótesis de trabajo que deberán ser contrastadas posteriormente. Dicha exploración nos permite distinguir algunos de los componentes más relevantes que en materia organizativa encontramos entre la población inmigrante colombiana residente en las distintas Comunidades Autónomas españolas en las que centramos nuestra atención: Madrid, Cataluña, Valencia, Andalucía y el País Vasco.

Particularmente, interesa identificar algunos de los rasgos que definen el modo en que los inmigrantes viven y trabajan en una sociedad diferente a la de su origen, de qué maneras enfrentan los desafíos de esa nueva realidad y cómo construyen espacios públicos nuevos para la solución colectiva de problemas

\footnotetext{
${ }^{13}$ Ibidem.
} 
también colectivos por los que son especialmente afectados; de qué modo establecen vínculos con otros inmigrantes y con los autóctonos y en qué medida su acción recoge los aprendizajes previos en materia organizativa de su contexto de salida.

Si bien, un estudio reciente como el de Luís Jorge Garay (2006:62), revela el precario nivel asociativo de los colombianos residentes en la Comunidad de Madrid, en cuanto cerca del $70 \%$ de los encuestados no es miembro de ninguna asociación en España y solamente el 17\% de alguna asociación de tipo recreativo o deportivo y otro $6 \%$ de alguna de orden religioso, así como el $83 \%$ tampoco pertenece a alguna de las asociaciones de colombianos en España y solo el 37\% tiene algún conocimiento de las mismas, las exploraciones preliminares que hemos adelantado en las Comunidades Autónomas señaladas nos han permitido constatar la existencia de diversas iniciativas colectivas de los inmigrantes con niveles diferenciales y desiguales recursos organizativos; conformación de organizaciones, asociaciones y otras formas de expresión colectiva, explicada en buena medida por la necesidad, la vulnerabilidad de su situación y la posibilidad de acceder a recursos para su atención.

De manera simultánea, y como lo señalamos antes, se puede observar una tendencia a vivir en la sociedad de destino adoptando un bajo perfil organizativo, con la intención de hacer menos visible su procedencia y las razones de su salida del país, además de aprovechar los posibles beneficios del anonimato en el país receptor $^{14}$; tendencia al anonimato explicada en términos de percepciones de mutuas desconfianzas y temores entre el colectivo de colombianos; percepciones que inhiben o limitan la opción de conformación de grupos, organizaciones y formas distintas de asociarse, del modo que lo vienen haciendo otros colectivos de inmigrantes. ${ }^{15}$

Encontramos que la asociación es el tipo de organización adoptada por la población inmigrante colombiana. En estas organizaciones los miembros son básicamente inmigrantes que han dejado Colombia por problemas de orden

\footnotetext{
${ }^{14}$ Entrevistas con inmigrantes colombianos en España realizadas entre octubre y diciembre de 2006.

${ }^{15}$ El fortalecimiento organizativo constituye hoy un objetivo del trabajo de atención a la población inmigrante por parte de la Comisión Española de Ayuda al Refugiado CEAR, a partir de la existencia de organizaciones de distintos colectiva de inmigrantes a las que ha prestado asesoría y capacitación, de las cuales han hecho parte algunos colectivos de inmigrantes colombianos. Véase: Federación Estatal de Asociaciones de Inmigrantes y Refugiados en España FERINE; Boletín CEAR.
} 
económico -desempleo, pérdida del poder adquisitivo, desestímulo a la actividad empresarial a pequeña escala- y, motivados por expectativas de encontrar una mejor oferta laboral-. Aparecen también, en menor proporción, asociaciones de refugiados políticos, cuyas razones de salida de Colombia están asociadas a la evolución reciente del conflicto armado, a su escalamiento -amenazas, persecuciones, asesinatos de defensores de derechos humanos, desplazamientos forzados de población-.

Los intereses de los miembros de las asociaciones, por su formación semiprofesional y profesional, están en consonancia con obtener condiciones de vida que les posibilite instalarse en la sociedad de llegada. Dicho de otra manera, estas asociaciones quieren hacer de España una sociedad de acogida. Los miembros prácticamente han descartado la posibilidad de retornar a Colombia en el mediano plazo, por ello su preocupación es, básicamente, procurarse mejores condiciones para adaptarse al contexto de llegada. ${ }^{16}$ Condiciones que ven favorecidas por su adscripción a procesos organizativos que les facilite una mayor interlocución con los organismos estatales y privados de la sociedad española.

En este escenario, se explica que los esfuerzos individuales para conformar y consolidar una asociación, no siempre traducen intereses colectivos; en ocasiones su búsqueda está en estrecha relación con el mejoramiento de condiciones de vida familiar y laboral de quienes han decidido instalarse por largo tiempo. La gestión de recursos, como uno de los objetivos de la conformación de las asociaciones, es también, un mecanismo para procurarse un camino que al satisfacer necesidades inmediatas potencie la estabilización socioeconómica de sus miembros en la sociedad de llegada. Esto no significa que el perfil de las asociaciones de inmigrantes colombianos responda únicamente a esta condición; da cuenta, eso sí, del impacto que sobre el proceso organizativo puede tener la búsqueda de soluciones a una situación de precariedad económica. No obstante, sus objetivos no se reducen a ello, y al contrario, la diversidad de acciones y metas de los colectivos, dan cuenta de las distintas dimensiones de la vida asociativa en el país de llegada, de los intereses plurales que comparten y de la diversidad de las iniciativas ensayadas para favorecer el proceso de adaptación y/o acomodación a las nuevas circunstancias.

\footnotetext{
${ }^{16}$ Entrevista. Director del periódico "El Boga". Vitoria, 30 de noviembre de 2006.
} 
Ahora bien, el despliegue de acciones encaminadas a atender otros asuntos no es ajeno a las asociaciones de inmigrantes colombianos; una amplia gama de actividades suelen ser desplegadas para concitar la solidaridad internacional ante la agudización del conflicto colombiano; actividades de tipo cultural y político que surgen, fundamentalmente, del seno de las organizaciones de refugiados cuyo perfil responde en mayor medida a motivaciones de esta naturaleza ${ }^{17}$.

En cualquier caso, las asociaciones, por los recursos que gestionan, logran contar con algún personal remunerado que atienda las labores asignadas por los asociados. Y aunque el voluntariado es un factor importante para desplegar las actividades de las asociaciones, la gestión posibilita, paulatinamente, crear una estructura organizativa que permite diferenciar entre las funciones de los asociados y el papel de los funcionarios.

Finalmente, si bien estamos todavía frente a resultados preliminares de la investigación, podría señalarse que no hay condiciones particulares de los inmigrantes colombianos para definir reivindicaciones diferentes a los inmigrantes de otros colectivos radicados en España. Sin embargo, las condiciones de salida -el contexto de violencia prolongada y el deterioro de las condiciones socioeconómicas de los colombianos- deviene en espejo permanente de las iniciativas organizativas del colectivo de inmigrantes colombianos, atravesando, de algún modo, su naturaleza, su forma y su papel en la sociedad española; pero además, condicionando de distinta forma su proceso de inserción y sus expectativas de retorno. La necesidad de algunos colectivos, sobre todo de los refugiados, de divulgar en España la crisis humanitaria que padece Colombia por la prolongación de una guerra irregular interna y la exclusión social que a ella subyace, pone de presente, entonces, la potencialidad que tienen los colectivos de inmigrantes para inscribir y denunciar la violación sistemática de los derechos humanos ante las redes internacionales de protección del Derecho Internacional Humanitario y para situar la crisis del país en las agendas de discusión pública de la que podría denominarse la sociedad civil global.

\footnotetext{
${ }^{17}$ Entrevista. Colectivo Bachué, Vitoria, 30 de noviembre de 2006.
} 


\section{Referencias}

Actualidad-Terra (2006) Refugiados colombianos denuncian en Gijón las violaciones a los DDHH cometidas por el Gobierno de Uribe, 20-6-2006, En http://actualidad.terra.es/articulo/refugiados gijon ddhh gobierno uribe 939857.htm, Accedido el 21-6-2006.

Ahumada Beltrán, C. y Moreno Durán, A. (2005). Prioridades del nuevo orden mundial y desplazamiento forzado de colombianos hacia Ecuador, La Insignia.

Alberich, T. (1993). "La crisis de los movimientos sociales y el asociacionismo de los años noventa". Documentación Social, 90: 101-114

Arango, J. (1993). "Las migraciones internacionales a fines del siglo XX: realidad y teoría", en VV.AA. Escritos de Teoría Sociológica en Homenaje a Luis Rodríguez Zúñiga, Madrid: Centro de investigaciones sociológicas

Ariño Villarroya, A. (2004). "Asociacionismo, ciudadanía y bienestar social". Papers 74: 85-110

Ariño Villarroya, A. y Cucó i Giner, J. (2001). "Las organizaciones solidarias. Un análisis de su naturaleza y significado a la luz del caso valenciano". Revista Internacional de Sociología, No 29: 7-34, Mayo-Agosto.

Barber, B. (2001). "Un marco conceptual: política de participación" En La democracia en sus textos. Águila, R. del y Vallespín, F. (et al.) Madrid: Alianza Ed. (pp. 281-297).

Barber. B. R. (2000). Un lugar para todos. Cómo fortalecer la democracia y la sociedad civil. Barcelona: Paidos.

Barthélemy, M. (2003). Asociaciones: ¿una nueva era de la participación?. Valencia: Tirant lo Blanch.

Beck, U. (2000): La democracia y sus enemigos. Barcelona: Paidós.

Blanco, C. (2004). "Las migraciones internacionales: procesos históricos. Conceptos básicos sobre migraciones internacionales. Las migraciones internacionales en la historia contemporánea: factores influyentes, flujos y efectos". En Trabajo social y educación social con inmigrantes en países receptores y de origen, César Manzanos (coord.), Málaga: Ediciones Aljibe, pp. 37-50.

Boletín Oficial del Estado (BOE), Madrid.

Brisson, M. (1997). Migraciones... ¿Alternativa insólita? San José de Costa Rica: DEI

Cachón, L. (2001). "La formación de la "España Inmigrante": mercado y ciudadanía", Revista española de Investigaciones Sociológicas.

Cárdenas, M. y Mejías, C. (2006). Migraciones internacionales de colombianos: ¿qué sabemos? FEDESARROLLO.

http://www.fedesarrollo.org:82/mcardenas/images/papers/migracionesinternacionalesColombi a/migraciones internacionales colombia presentacion.pdf Accedido el 23/04/2006

Castels, S. (2000). "La migración internacional a comienzos del siglo XXI: Tendencias y problemas mundiales". International Social Sciencie Journal, 165.

CEAR (2005). Informe 2005, En http://www.cear.es/upload/Informe\%202005\%20de\%20CEAR.pdf Accedido el 19-6-2006.

Cefaï; M. A. (2004): "Acción asociativa y ciudadanía común: ¿la sociedad civil como matriz de la res pública" En Aprendiendo a ser ciudadanos. Benedicto, J. y Morán, M. L. Madrid: INJUVE.

CEMLA-BID/FOMIN (2005). Colombia: flujos migratorios y remesas de trabajadores. Seminario de remesas de trabajadores, México D.F., octubre 14 y 15. En http://www.cemlaremesas.org/PDF/seminariomx/0510MX-ES-PPT-Colombia.pdf . Accedido el 24/04/2007

CODHES INFORMA (2004) "Colombia, Estados Unidos y los países vecinos frente al desplazamiento forzado. ¿Asunto militar o humanitario?" BOLETÍN INFORMATIVO DE LA CONSULTORÍA PARA LOS DERECHOS HUMANOS Y EL DESPLAZAMIENTO No. 55. Bogotá, diciembre 2004.

Cohen, J. y Arato, A. (2000): Sociedad civil y teoría política. México: FCE.

Cohen, J. y Rogers, J. (1998): "Asociaciones secundarias y gobierno democrático". Zona Abierta 084/085 pp. 3-122.

Cohen, J. y Rogers, J. (1998): “Solidaridad, democracia y asociación”. Zona Abierta 084-085.

Colectivo IOE (1999). Inmigrantes, Trabajadores, Ciudadanos. Una visión de las migraciones desde España, Universitat de Valencia: Valencia. 
DANE-Departamento Administrativo Nacional de Estadística (2005). Aproximación a la migración internacional en Colombia a partir del Censo General 2005, En http://www.dane.gov.co/censo/files/presentaciones/migracion internacional.pdf Accedido el 18-6-2006

DAS/DANE/OIM (2003). Anuario 2003. Movimientos migratorios internacionales de Colombia. En http://www.oim.org.co/anexos/documentos/publicaciones/libro71.pdf Accedido el 20/04/2007

DAS-Departamento Administrativo de Seguridad (2005). Estadísticas Migratorias. http://www.das.gov.co/ Accedido el 20/04/2007

De Sousa Santos, B. (1998). La globalización del derecho. Los nuevos caminos de la regulación y la emancipación, ILSA: Bogotá.

Diario Oficial de la Comunidad Europea (DOCE), Diario Oficial C, Diario Oficial L, Luxemburgo

Díez, A. (2006). Análisis de la migración colombiana en España. Volumen y perfil sociodemográfico de la inmigración colombiana en Sevilla: 1995-2004. Tesina para la obtención del DEA en la Universidad de Sevilla. Sevilla: inédita.

Donati, P. (2002). "Ciudadanía y sociedad civil: dos paradigmas (ciudadanía lib/lab y ciudadanía societaria)". REIS 98: 37-64

Eliasoph, N. (1998). Avoiding politics: how Americans produce apathy in everyday life. Cambridge: Cambridge University Press.

Etzioni, A. (2005) "Por qué la sociedad civil no es lo suficientemente buena". Revista del CLAD Reforma y Democracia, № 33, Octubre. Caracas [Recurso electrónico].

Garay Salamanca, L.J. (2006). Estudio sobre características socio-económicas, integración social e inserción laboral de los colombianos en la Comunidad de Madrid (España). Informe final de Proyecto COL/02/052 - 00012043. Madrid: inédito.

Grau, Elena y Ibarra, P. (coord.). (2003). Nuevos escenarios, nuevos retos en la red. Anuario de Movimientos Sociales 2002. Barcelona: Icaria.

Guarnizo, L.E. (2003) "La migración transnacional colombiana: implicaciones teóricas y prácticas". En Colombia nos Une. Memoria Seminario sobre migración internacional colombiana y la conformación de comunidades transnacionales. Bogotá, Ministerio de Relaciones Exteriores, junio 18 y 19 de 2003.

Hellgren, Z. (2007). "(De) construyendo la ciudadanía europea. El inmigrante como actor social y político". Universidad de Estocolmo. Ponencia presentada en el V Congreso sobre la Inmigración en España: Migraciones y desarrollo humano. Valencia, marzo de 2007

INE-Instituto Nacional de Estadística (2003a). Anuario Estadístico de España (AEE) 2002-2003. Demografía En http://www.ine.es/prodyser/pubweb/anuario0203/0203demografia.pdf Accedido el 20-04-2007

Jerez, A. y Revilla, M. (1997): "El Tercer Sector. Una revisión introductoria a un concepto polémico" En ¿Trabajo Voluntario o participación?. Elementos para una sociología del Tercer Sector. Jerez, A. (coord.) Madrid: Tecnos.

Jiménez, M. J. y Franco, R. (coords.) (2002), Nuevas estrategias para una política de inmigración solidaria, Sevilla: Mergablum: Sevilla.

Keane, J. (1992): Democracia y Sociedad Civil. Madrid: Alianza Ed.

Legislación vigente en materia de Derechos Humanos reconocidos a los extranjeros en el ámbito internacional, europeo y estatal.

Meister, A. (1971). Participación social y cambio social: materiales para una sociología del asociacionismo. Caracas: Monte Avila Ed.

Melucci, A. (1998). "La experiencia individual y los temas globales en una sociedad planetaria" en Los movimientos sociales. Transformaciones políticas y cambio cultural. Ibarra, P y Tejerina, B. (eds.) Madrid: Ed. Trotta. pp. 361-381.

Mezzadra, S. (2005). Derecho de fuga. Migraciones, ciudadanía y globalización. Madrid: Traficantes de Sueños.

Ministerio de Trabajo y Asuntos Sociales, ed. (2005) Anuario Estadístico de Inmigración. Madrid. En http://extranjeros.mtas.es/es/general/Anuario2005.pdf Accedido el 23-04-2007

Ministerio del Interior (1999). Anuario Estadístico de Extranjería 1999 En http://extranjeros.mtas.es/es/general/Anuario1999 ANEXT99.pdf Accedido el 25-04-2007

Ministerio de Relaciones Exteriores, Programa Colombia Nos Une. (2003) "Memorias del seminario sobre migración internacional colombiana y la conformación de comunidades trasnacionales".

Morales Diez de Ulzurrum, L. (2004): "El asociacionismo político en Europa". Zona Abierta 106/107 (pp. 7-63).

Morales, L. (2005): “¿Existe una crisis participativa? La evolución de la participación política y el asociacionismo en España”. Revista Española de Ciencia Política, 13: 51-87.

AIBR. Revista de Antropología Iberoamericana. www.aibr.org

Volumen 2, Número 3. Septiembre-Diciembre 2007. Pp. 521-549

Madrid: Antropólogos Iberoamericanos en Red. ISSN: 1695-9752 
Naïr, S. (2005): "El liberalismo 'de izquierda"'. El País digital

Nieto, Lucía (2006), Colombianos migran a España: quiénes y por qué: En http://www.universia.net.co/laboralempresarial/destacado/colombianosmigranaespanaquienesyporque.html Accedido el 20-62006

Noticias Hispanista (2006), Unos 18.000 colombianos votarán desde España en las presidenciales de mañana, 27-5-2006, http://noticias.hispavista.com/internacional/20060527234840/-Unos18000-colombianos-votaran-desde-Espana-en-las-presidenciales-de-mananal Accedido el 206-2006

Ojeda, G (2006). Una mirada de la familia y la migración: resultados del módulo migración internacional en la Encuesta de Demografía y Salud de 2005. Colombia nos une. Memorias II Seminario sobre migración internacional colombiana y la conformación de comunidades transnacionales, 15 y 16 de julio de 2006. Bogotá: Ministerio de Relaciones Exteriores de Colombia, pp. 53-57. En http://www.oim.org.co/anexos/documentos/publicaciones/libro128.pdf Accedido el 20/04/2007

Ortiz, J. (2002). "Incidencia económica de la población extranjera migrante en Andalucía: una caracterización." En Inmigración extranjera en Andalucía. II Seminario sobre la investigación de la inmigración extranjera en Andalucía, Consejería de Gobernación, Junta de Andalucía.

Pedone, C. (2003). "Tú siempre jalas a los tuyos". Cadenas y redes migratorias de las familias ecuatorianas hacia España. Universitat Autónoma de Barcelona.

Pumares, P., García, A. y Asensio, A. (2006) La movilidad laboral y geográfica de la población extranjera en España, Madrid: Ministerio de Trabajo y Asuntos Sociales. En http://extranjeros.mtas.es/es/general/movilidad\%20laboral.pdf Accedido el 25-04-2007.

Puyol, F. (2006). Difícil situación laboral para colombianos en España, En http://www.laesquinaregional.com/ediciones/ed09/09 desde la otra orilla.htm Accedido el 20-6-2006.

Ramírez, F. y Ramírez, J. P. (2005). La estampida migratoria ecuatoriana. Crisis, redes transnacionales y repertorios de acción migratoria. Quito, Centro de Investigaciones CIUDADUNESCO-ABYA YALA-ALISEI, diciembre.

Roitter, M. (2004): "El tercer sector como representación topográfica de la sociedad civil" Políticas de ciudadanía y sociedad civil en tiempos de globalización. Mato D. (coord) Caracas: FACES, Universidad Central de Venezuela. pp. 17-32.

Rojas, Ernesto $\left(2006^{a}\right)$, Algunas reflexiones sobre el censo 2005 en Colombia [por el director del DANE] En http://www.dane.gov.co/files/censo2005/presenta director.pdf, Accedido el 18-62006

Salamon, M. L. (1999): La sociedad civil global. Las dimensiones del sector no lucrativo. Madrid: Fundación BBVA.

Sánchez Herrera, E. (2006). Asociacionismo, sociedad civil e integración sociopolítica de los individuos. El debate teórico contemporáneo en torno al asociacionismo. Trabajo de Investigación, Universidad Complutense de Madrid. Inédito.

Subirats, J. (ed.) (1999). ¿Existe sociedad civil en España?: Responsabilidades colectivas y valores públicos? Madrid: Fundación Encuentro.

Tilly, Ch. (1998): "Conflicto político y cambio social" en Ibarra, P. y Tejerina, B. (eds.): Los movimientos sociales. Transformaciones políticas y cambio cultural. Madrid: Ed. Trotta.

Tilly, Ch. (1990). "Modelos y realidades de la acción colectiva popular". Zona Abierta, 54/55: 167-195.

Tilly, Ch. (1978). From Mobilization to Revolution. McGraw-Hill Publishing Company.

Tocqueville, Alexis de (2002): La democracia en América, 1 y 2. Madrid: Alianza Editorial.

Vidal López, R. C. (2005). "Derecho global y desplazamiento interno. La creación, uso y desaparición del desplazamiento forzado por la violencia en Colombia". 